\title{
Functional Stylistic Analysis: Transitivity in English-Medium Medical Research Articles
}

\author{
Shuyuan Zheng ${ }^{1}$, An Yang ${ }^{1} \&$ Guangchun $\mathrm{Ge}^{1}$ \\ ${ }^{1}$ Department of Foreign Languages, Fourth Military Medical University, Xi'an, Shaanxi, China \\ Correspondence: Guangchun Ge, Department of Foreign Languages, Fourth Military Medical University, Xi'an \\ 710032, Shaanxi, China. Tel: 86-29-8477-9761. E-mail: guangcge@fmmu.edu.cn
}

Received: February 14, 2014 Accepted: March 18, 2014 Online Published: March 26, 2014

doi:10.5539/ijel.v4n2p12

URL: http://dx.doi.org/10.5539/ijel.v4n2p12

\begin{abstract}
In this paper, we report a corpus-based transitivity analysis on the six process types employed in realizing some stylistic features of the English-medium medical research article (RA). By studying 25 complete English-medium medical RAs from five SCI English-medium medical journals, we find that the transitivity system plays an important role in the realization of stylistic features of the English-medium medical RA and that the application of different process types in the different sections may be associated with the purposes and style requirements of each section. Proper application of the process types from the perspective of the different style requirements may enable nonnative English speaking (NNES) medical RA writers to produce stylistically appropriate medical RAs, and eventually lead to the ultimate goal of successful publication.
\end{abstract}

Keywords: functional stylistic analysis, transitivity, medical research article, corpus-based, process type

\section{Introduction}

Stylistics is defined as "the study of style" by Wales (1989, p. 437) and stylistic analysis is generally concerned with the uniqueness of a text, with what is peculiar to the uses of language in a literary or non-literary text for delivering the message. For different purposes in the study of style, linguists (Crystal \& Davy, 1969; Fowler, 1981; Freeborn, 1996; Short, 1996) have conducted stylistic analyses in a variety of discourses with diverse linguistic models based on Structural Linguistics, Transformational Generative Grammar, Systemic Functional Grammar, Speech Act Theory or Conversational Analysis Theory. Functional stylistic analysis, based on Systemic Functional Grammar (SFG), has caught the attention of many researchers (Halliday, 1988; O' Toole, 1988; Shen, 1997, 2002; Zhang, 2005). Systemic Functional Grammar, put forward by Halliday (Halliday, 2000; Halliday \& Matthiessen, 2004), pays great attention to how the speakers generate utterances and texts to convey their intended meanings. According to SFG, language has three (ideational, interpersonal, and textual) metafunctions. All the three metafunctions are reflected in a huge system network, which specifies all the meaning potentials. Transitivity, also termed by Halliday (1967, p. 37) as "transitivity system", is concerned with the type of process expressed in the clause, with the participants in this process (animate and inanimate) and with various attributes and circumstances of the process and the participants. Being pertinent to the ideational function, i.e., the semantic content of language, transitivity is geared towards the grammar of experience that reflects the representations of the speaker's world (Halliday \& Matthiessen, 2004). Transitivity, as an important sub-network of the system network, is now receiving more and more attention in functional stylistic analysis.

The research article (RA) is considered to be the most highly valued genre used by scientific discourse communities (Knorr-Cetina, 1981; Swales, 2001) and it is often difficult for researchers to write successful RAs, especially for non-native English speaking (NNES) writers (Okamura, 2006; Paltridge, 1993). The medical RA is a highly technical form with a standard format for the presentation of information (Nwogu, 1997). As style is no less important in scientific writing than in poetry (Aaronson, 1977; Estevez \& Pique, 1997), writing a medical RA, for NNES writers, requires careful attention to style as well as language proficiency. However, NNES medical RA writers are often faced with difficulties in constructing stylistically appropriate texts. This study intends to contribute information to the existing research on transitivity in the RA by exploring the process selection or the choice of process types in realizing certain stylistic features of English-medium medical RAs. Writing with awareness of the relation between the transitivity choice of processes and the stylistic features of English-medium medical RAs may help NNES writers to construct stylistically appropriate RAs, and eventually 
lead to the ultimate goal of successful publication.

\subsection{Theoretical Background}

Transitivity is a semantic concept that examines how meaning is represented in the clause. By definition, transitivity in SFG is a process-centered system to encode and decode the experience and knowledge of human beings via lexicogrammar. It is Halliday (1967) who first stated that transitivity should be regarded as a property of clauses rather than verbs. Thompson (2000) has also explicated that transitivity is a system for describing the whole clause, rather than the verb and its object. The systems and networks of transitivity convey the user's experience of the external world of the senses and the internal world of the mind. The term "process" of transitivity refers to the "goings-on" in reality, for example, doing, happening and being. According to the latest edition of Halliday's (2008) An Introduction to Functional Grammar, transitivity system is composed of six processes that represent human experience in terms of: physical and physiological actions (Material and Behavioral), thinking and speaking actions (Mental and Verbal) and actions that signal the existence of something/someone and their identifying features (Existential and Relational). A variety of works (Halliday, 1967, 1976, 2001, 2008; Hopper \& Thompson, 1980; Langacker, 1987) have broadened the domain of transitivity and each could be regarded as a milestone in the study of transitivity.

In Halliday's transitivity system, the material process, a process of doing, usually describes concrete and tangible actions. The process expresses the notion that a participant, the Actor, "does" something-which may be done "to" some other participant, the Goal.

The mental process accounts for the process of sensing and involves not material actions but phenomena best described as states of mind or psychological events. A mental process should have two participants, the Senser (endowed with consciousness) and the Phenomenon (realized as a thing or as a fact).

The relational process, a process of being, serves to establish a relation between two separate entities. As the term "relational" suggests, something is being said to "be" something else in relational clauses. There are two types of relational processes: the attributive relational process with the Carrier and the Attribute as the participants, and the identifying relational process with the Identified and the Identifier as the participants.

The behavioral process is the process of typically human physiological and psychological behavior. Normally, a behavioral process has only one participant: the human Behaver. Being partly like the material process and partly like the mental process, the behavioral process is the least distinct of all the six process types, especially in the language of science.

The verbal process is the process of saying. It characteristically involves three participants: the Sayer, the Receiver and the Verbiage. The Sayer, the participant responsible for the verbal process, is typically but not necessarily conscious. The Receiver is the participant to whom the saying is directed. The Verbiage is characterized by nouns expressing verbal behavior, such as question, story and report.

The existential process represents existence or happening through a process and a participant that is being said to exist, the Existent. Generally speaking, the existential process is realized by the There-construction in English which has no representational function and there are no human participants in existential processes. The six processes categorized in Halliday's approach to transitivity are illustrated in Table 1. 
Table 1. Process types, their meanings and characteristic participants defined by Halliday (2008)

\begin{tabular}{|c|c|c|c|}
\hline $\begin{array}{l}\text { PROCESS } \\
\text { TYPE }\end{array}$ & $\begin{array}{l}\text { Category } \\
\text { Meaning }\end{array}$ & $\begin{array}{l}\text { Participants, } \quad \text { Directly } \\
\text { Involved }\end{array}$ & Participants, Obliquely Involved \\
\hline $\begin{array}{c}\text { material: } \\
\text { action } \\
\text { event }\end{array}$ & $\begin{array}{l}\text { "doing" } \\
\text { "doing" } \\
\text { "happening" }\end{array}$ & Actor, Goal & $\begin{array}{l}\text { Recipient, Client; Scope; Initiator; } \\
\text { Attribute }\end{array}$ \\
\hline behavioral & "behaving" & Behaver & Behavior \\
\hline $\begin{array}{l}\text { mental: } \\
\text { perception } \\
\text { cognition } \\
\text { desideration } \\
\text { emotion }\end{array}$ & $\begin{array}{l}\text { "sensing" } \\
\text { "seeing" } \\
\text { "thinking" } \\
\text { "wanting" } \\
\text { "feeling" }\end{array}$ & Senser, Phenomenon & \\
\hline verbal & "saying" & Sayer, Target & Receiver; Verbiage \\
\hline $\begin{array}{l}\text { relational: } \\
\text { attribution } \\
\text { identification }\end{array}$ & $\begin{array}{l}\text { "being" } \\
\text { "attributing" } \\
\text { "identifying" }\end{array}$ & $\begin{array}{l}\text { Carrier, Attribute } \\
\text { Identified, Identifier; Token, } \\
\text { Value }\end{array}$ & $\begin{array}{l}\text { Attributor, Beneficiary } \\
\text { Assigner }\end{array}$ \\
\hline existential & "existing" & Existent & \\
\hline
\end{tabular}

Halliday (2008) has set some principal criteria for distinguishing the process types (Appendix A) and some examples of the verbs proposed by Halliday (2008) and Thompson (2000) in identifying the types of processes are listed in Appendix B. Some clauses, however, can be classified under more than one type of process, depending on their use in the text. Clauses with verbs such as suggest and indicate can be categorized as relational processes when the nominal elements in the transitivity structure are abstractions or as mental processes when the meaning of the verb is making us think that. In the latter sense, the verbs are sources of projections according to Halliday and Martin (1993). For example:

(1) A recent study suggested a rate of failure to obtain an image of only 0.5 percent. (relational process)

(2) Some studies have suggested that the inhibition of ACAT1 may promote atherosclerosis. (mental process)

Similarly, the clause with the verb show is a verbal process when it has an explicit Sayer and projects what is said but it is a relational process when it relates abstract nominal elements. For example:

(3) Research shows that a high-fiber diet may protect people from bowel cancer. (verbal process)

(4) These figures show a $25 \%$ increase of bowel cancer. (relational process)

The presence, absence or high/low frequency of the six process types in a particular type of text may have different implications. In his book Discourse Cohesion and Coherence, Hu (1994) has stated that the use of a relatively larger proportion of a certain type of process is one of the elements reflecting the text characteristics. $\mathrm{Hu}$ has also concluded in the book that the material process as the dominant type characterizes technical directions and medical instructions; the verbal process ranks after the material process in English broadcasting; the existential process usually appears in the description of travel notes; and the mental process is mainly used in literary works to reveal the personality of relevant figures.

\subsection{Some Previous Studies on Transitivity}

Researches on the analysis of transitivity have proved that the transitivity system plays a crucial role in reading and writing texts in various discourses, both literary discourses and non-literary discourses.

The analyses of the transitivity system in literary discourses by many researchers (Bonifacio, 2011; Halliday, 1971; Liu, 1998; Short, 1976) demonstrate that the analyses of the transitivity system in literary discourses help to reveal the personalities of the heroes the writers depict and contribute to a better understanding of the stylistic features in literary discourses. The analyses of the transitivity system in non-literary discourses, which have been prompted in recent years, have focused on the expressivities of transitivity in describing the text features. Yang 
(2001) conducted a transitivity analysis on editorials and she reported that the specific stylistic feature of editorials, i.e., narration interspersed with comments, was realized by the predominant use of the material process $(55.9 \%)$ and the relational process $(27.4 \%)$. Wu's (2004) findings of a high frequency of mental processes in the English e-mails used for academic discussion mirrored the interactive style of the discourse. Babaii and Ansary (2005) studied academic book reviews from discipline-related professional journals (physics, sociology, and literature) and their study showed that book reviewers in different disciplines favored different devices in conveying their messages and in striking a balance between impersonality and interaction. Applying systemic functional theories, Gong and Fang (2005) analyzed the process types of the transitivity system in the discourse taken from court debates and they reported that the ideational function in the court discourse was mainly realized through the processes of transitivity.

Some researchers have conducted some transitivity analyses on experimental research articles (RAs) in different fields to reveal the relationship between the transitivity structure and certain specific stylistic features of RAs. Martinez (2001) analyzed the impersonality in RAs by analysis of the transitivity structure characterizing the experimental RAs in a corpus of 21 experimental RAs in the fields of physical, biological and social sciences. Her analysis of the application of transitivity processes revealed a tension between the need to present findings objectively and the desire to persuade readers of their validity in an appropriate style. Her findings showed that the preference for impersonal constructions in RAs may result from the strategic choices of process types made by the writers. From the perspective of genre analysis, Pang and Chen (2007) investigated the features of transitivity in different sections of RAs by analyzing six RAs in psychology and materials science and they reported that the different percentages of transitivity processes used in the four sections of an RA reflected different objectivity degrees in the four sections and the different objectivity degrees constrained the authors' choice of language. The findings of these studies on the transitivity features and choices all add to our understanding of the functional role of transitivity in RAs in general, but research conducted exclusively for process types in medical RAs seems rare.

RAs constitute one of the most important channels for presentation and exchange of new findings in today's medical arena. A number of studies (Adams-Smith, 1983; Grant \& Laird, 1997; Hemminki, 1982; Nwogu, 1997) have shown that the phenomenon of bad writing amongst medical practitioners is a long-standing one and that medical researchers face enormous difficulties with writing research articles and medical RAs tend to be poorly organized or structured. A better understanding and proper choice of process types in an English-medium medical RA will help NNES medical RA writers to produce stylistically appropriate medical RAs for publication. However, to the best of our knowledge, no study has been reported focusing on the transitivity structure and choice of English-medium medical RAs. To fill this gap, we conducted this transitivity analysis to explore the transitivity patterns employed in realizing certain stylistic features of English-medium medical RAs and the findings of this study we hope could be applied in writing classes of English medical RAs for NNES writers.

\section{Method}

\subsection{Corpus Establishment}

Though some researchers have suggested that the corpus size be as large as possible, some other researchers have argued that to become familiar with a highly specific text-type, even a small specialized corpus may provide more plentiful documentation of many features of that type than can a large general one (Aston, 1997; Roe, 2000). In our case, mostly for the practicality and feasibility and in line with the view put forward by Tribble (1997) that small representative corpora are favored for specific purposes, we established a corpus of 25 sample medical RAs. The corpus was compiled with 25 complete (Note 1) English-medium experimental medical RAs from five SCI-indexed English-medium medical journals published in 2004 and 2005 either in the United States or in the United Kingdom (See at Supplementary data). Though the five selected journals were in different medical fields and of different impact factors, each journal occupied a very influential position in its own field for the relatively high impact factor (2005) in the field. The high reputation of these journals ensured that the RAs published in these journals were "situationally effective" and were the results of "expert performance" (Bazerman, 1994, p. 23, 131). The five selected journals are: New England Journal of Medicine (J1, IF 38.57), Journal of the American Medical Association (J2, IF 24.831), Biology of Reproduction (J3, IF 2.55), Journal of Cell Biology (J4, IF 11.602) and European Journal Pharmacology (J5, IF 2.432). The sample RAs selected for the corpus all followed the Introduction-Method-Results-Discussion (IMRD) framework, with a length ranging from 2500 to 4000 words (3574 \pm 1094$)$.

For the 25 sample RAs to be included in the corpus, we conducted a two-round random stratified sampling. Each of the five journals selected for the corpus was taken as one stratum to ensure that the candidate RAs all had 
equal opportunities to be selected as sample RAs. In the first round, all the criteria-meeting RAs in the available issues of each journal were identified and numbered and then 20 sample RAs were selected from each journal/stratum (10 from the issues published in 2004, 10 from the issues published in 2005) using the table of random numbers. A total of 100 sample RAs were thus randomly selected from all the issues of the five journals published in 2004-2005. In the second round, 25 sample RAs with 89,350 words (5 from each of the 5 journals/strata) were randomly selected from the 100 sample RAs obtained in the first round and they made up the corpus.

\subsection{Data Collection and Analysis}

\subsubsection{Identification of Ranking Clauses and Transitivity Processes}

A language is a complex system composed of multiple levels. According to Halliday (2000), ranking clauses form a separate rank on the rank scale and they do not form part of a larger clause. Ranking clauses function prototypically as constituents of the higher unit, of which embedded clauses function as constituents. Thus, for the transitivity analysis of the processes in the medical RAs in the samples in our corpus, we first identified all the ranking clauses using Halliday's method (2008) as shown by the following examples:

(5) || Our study demonstrates the value of intravascular ultrasonography in assessing the effect of therapies on the atherosclerotic disease process. ||| (J1-1)

(6) III The target study population excluded 648 residents in services [[that seldom use CPOE: pathology, podiatry, occupational medicine, anesthesia, radiology, radiation oncology, ophthalmology, and dermatology.]] ||| (J2-2)

Example 5 was identified as one single ranking clause marked off by the symbol $\|$. Example 6 was identified as one clause complex marked off by the symbol III, with one ranking clause "The target study population excluded 648 residents in services" and one embedded clause "that seldom use CPOE: pathology, podiatry, occupational medicine, anesthesia, radiology, radiation oncology, ophthalmology, and dermatology" marked off by [[ ]]. As the embedded clause is not at the same level of the structure as the ranking clause (Thompson, 2000) and functions as a constituent (Halliday, 2008), embedded clauses, though identified in our study, were excluded from the counting in data collection.

After marking off all the clauses, we proceeded to identify the process types of the marked-off ranking clauses. The six processes defined by Halliday (2008), e.g., material process, mental process, relational process, verbal process, existential process and behavioral process, were identified and categorized by strictly referring to the process categorization, process definitions and instantiations for process types set by Halliday (2008). For example:

(7) || (1) Our results indicate || (2)that dyspnea is an important symptom among patients with suspected and known coronary artery disease || (3) and imply || (4) that when dyspnea is present, || (5) the likelihood of death from cardiac causes and from any cause is increased. || $\mid(\mathrm{J} 1-5)$

Example 7 was a clause complex with five ranking clauses. Ranking clauses (1) and (3) were identified as mental processes, as the verbs indicate and imply clearly showed the meaning of SENSING or cognition. Ranking clauses (2) (4) were identified as relational processes, as the verb "is" in both clauses set up BEING or a relation between two separate entities, respectively "dyspnea" and "symptom", and "dyspnea" and "present". Ranking clause (5) was identified as material process, for the verb "increase" showed the DOING of some Actor, though the Actor did not appear in the ranking clause.

\subsubsection{Analysis of the Data}

All the process types identified were first categorized at the section level of the medical RAs in the corpus. The sectional occurrence frequencies of the process types were counted manually, then added up in each sample and recorded. Spearman test was conducted for the correlation between the frequency of each process type used in the section and the length of the section.

\subsection{Reliability of the Analyses}

To enhance the validity of the data for the statistical analysis, the researcher re-coded the process types in 5 medical RAs from the corpus three months after the initial identification of the process types. Kappa coefficient $(k)$ was used to test the intra-rater reliabilities and the reliability index for the agreement between the initial coding and second coding of the process types was $(k=0.995)$. 


\section{Results and Discussion}

A total of 6158 ranking clauses were identified in the corpus and all the six process types categorized by Halliday (2008) were found to have occurred in our selected English-medium medical RAs. On the whole, the material process was the most frequently used process type in the samples in our corpus, with a total occurrence of $2835(46.04 \%)$, followed by the relational process $(1944,31.57 \%)$, the mental process $(799,12.97 \%)$, the verbal process $(393,6.38 \%)$, the existential process $(177,2.87 \%)$ and the behavioral process $(10,0.16 \%)$ in descending order of occurrence frequencies. The behavioral processes, the frequency of which may to some extent depend on the medical specialty of the RA analyzed, were excluded from the statistical analysis since its extremely low percentage of occurrence will not alter the end results. Thus, the total number of the ranking clauses for the statistical analysis was reduced from 6158 to 6148 (Table 2). Spearman correlation analysis showed that except for existential processes $\left(r_{s}=0.156, \mathrm{P}=0.455\right)$ and verbal processes $\left(r_{s}=0.274, \mathrm{P}=0.185\right)$ in the Method section and existential processes $\left(r_{s}=0.134, \mathrm{P}=0.522\right)$ in the Discussion section, all the other frequencies of the five calculated process types were positively correlated with the length of the sections in which they were used, with correlation coefficients ranging from 0.407 to 0.876 (all, $\mathrm{P}<0.05$ ).

Table 2. Occurrence frequencies and percentages of the five process types used in English-medium medical RAs in our corpus

\begin{tabular}{lcccccc}
\hline & Material & Relational & Mental & Verbal & Existential & \multirow{2}{*}{ Total } \\
& $\mathrm{F}(\mathrm{P})$ & $\mathrm{F}(\mathrm{P})$ & $\mathrm{F}(\mathrm{P})$ & $\mathrm{F}(\mathrm{P})$ & $\mathrm{F}(\mathrm{P})$ & \\
\hline Introduction & $268(40.54 \%)$ & $231(34.95 \%)$ & $91(13.77 \%)$ & $52(7.87 \%)$ & $19(2.87 \%)$ & 661 \\
Method & $1252(68.94 \%)$ & $281(15.48 \%)$ & $166(9.14 \%)$ & $101(5.56 \%)$ & $16(0.88 \%)$ & 1816 \\
Results & $635(37.37 \%)$ & $665(39.14 \%)$ & $210(12.36 \%)$ & $102(6.00 \%)$ & $87(5.12 \%)$ & 1699 \\
Discussion & $680(34.48 \%)$ & $767(38.89 \%)$ & $332(16.84 \%)$ & $138(7.00 \%)$ & $55(2.79 \%)$ & 1972 \\
Total & $2835(46.11 \%)$ & $1944(31.62 \%)$ & $799(13.00 \%)$ & $393(6.39 \%)$ & $177(2.88 \%)$ & 6148 \\
\hline
\end{tabular}

F stands for frequency; P stands for percentage;

\subsection{Analyses of the Six Process Types in English-Medium Medical Ras}

\subsubsection{Material Processes}

The material processes were found to be the most frequently used process type in the samples in our corpus. Li (2006) described the material process as expressing the notion that certain entity "does" something, including not only concrete, physical events but also abstract doings and happenings. Our findings of the high percentage of material processes in the English-medium medical RA (46.04\%) coincided with the percentage of the material processes used in experimental RAs (45\%) in the fields of physical, biological and social sciences (Martinez, 2001). These similar high percentages of material processes used in RAs clearly show that RA writers choose to use the material process when describing their experimental designs, observations and statistical analysis, and discoveries and contributions. The high percentage of material processes observed in RAs is also consistent with the dominantly high percentage of material processes reported both by Yang (2001) in her study of journalistic English news and editorials (55.9\%) and by Ju (2004) in her study of sports news (51.9\%). Our findings of the high percentage of material processes in English-medium medical RAs have corroborated Hu's (1994, p. 30) statement that "generally speaking, a text will contain a variety of transitivity process types but the material process will predominate, because the material world is the foundation in nature and the human activity is the fundamental guarantee of human existence".

Among the 2835 ranking clauses of material processes identified in this study, 1531 (54\%) had the Goals as the Subject and omitted the Actors, and most of the omitted Actors could safely be interpreted as the writers/researchers in the context. The omission of the Actors may evidence Nash's (1990) statement that authorial personality is excluded and the object of the research is foregrounded to convey the impression of objectivity. By omitting the Actors in the clause, the medical RA writers would not only present readers with more compact and concise information, but also concentrate their attention on the Goal in writing the medical RAs. The omission of the Actor may reflect medical RA writers' intention of shifting the focus of the readers more on the procedures and findings of their researches and distancing themselves from the text, which well exemplifies the objective and impersonal style of English-medium medical RAs. In the Method section where a 
clear, but detailed and objective description of the research design is supposed to be provided, the medical RA writer tends to portray what he is doing rather than his personal reactions to what he is doing. The material process is believed to perform the role of achieving this stylistic effect and is thus found most frequently used in the Method section. For example:

(8) || (1) Male Dunkin-Hartley guinea-pigs (250-500g) were anaesthetized with halothane I| (2) and killed by decapitation. I|| (3) The brain was then removed $\|$ (4) and the left and right hippocampi removed II (5) and bisected transversely into temporal and septal tissue blocks. ||| (6) Five to seven transverse slices (500 $\mu$ m thick) from the temporal section were prepared on a Vibratome (Vibratome Company, Missouri, USA). I|| (7) The slices were stored at room temperature in an artificial cerebral spinal fluid (CSF) of the following composition (in $\mathrm{mM}$ ): $\mathrm{NaCl} \mathrm{118,} \mathrm{KCl} 3, \mathrm{NaHCO}_{3} 25, \mathrm{NaH}_{2} \mathrm{PO}_{4}$ 1.2, $\mathrm{MgCL}_{2}$ 1, CaCl 1.5 , D-glucose 10 (gassed with $95 \% \mathrm{O}_{2} / 5 \% \mathrm{CO}_{2}$ ). || (J5-1)

In example 8, the author described in the Method section two steps of an experiment: slice preparation and recording. Seven ranking clauses were identified in the discourse, all of which were material processes containing the Goal, the objects of research, but omitting the Actor, the researchers. In the absence of the Actor but with the presence of such concrete verbs as anaesthetize, kill, remove, bisect, prepare and store, a clear and detailed description of the research was presented with a strong implication of impersonality, focusing the readers' attention on the research procedures and not the researchers.

\subsubsection{Relational Processes}

Relational processes were found to be the second most frequently used process types in the discourse of English-medium medical RAs under study. Halliday (2000) has defined the relational process essentially as a process of Being and the relationship between two things or concepts. Halliday also (1985) stated that in scientific writing, the relational process perhaps tended to be the most informative process. As medical RAs are typical texts of descriptions, argumentation or exposition, it is very natural that relational processes are favored by medical RA writers in their attempts to write an informative medical RA. As relational clauses serve to characterize and to identify (Halliday \& Matthiessen, 2004), the use of the relational process will add descriptiveness and preciseness to the medical RA.

Halliday (2000) sub-categorized the relational processes into attributive relational process and identifying relational process. In our study, we found that the attributive relational process was often used to describe the quality and the attribute of the medical facts. For example:

(9) || ...LH-stimulated prostaglandins (PGs) produced within the periovulatory follicles are also essential for follicle rupture and oocyte release. ||| (J3-5)

(10) ||| The observed median MoM value of 0.61 for unconjugated estriol was substantially lower than almost all previously published estimates.||| (J1-2)

In Example 9, the Carrier "LH-stimulated prostaglandins (PGs) produced within the periovulatory follicles" was described as "essential" and in Example 10, the Carrier "The observed median MoM value of 0.61 for unconjugated estriol" was described as "lower". Both Attributes "essential" and "lower" have presented readers with some new information about the respective Carrier. The description of the attributes of medical phenomena gives readers more information about the theme in point.

The most familiar and probably the most frequently used way of defining or elaborating terms is to define technical terms through an identifying relational clause (Halliday, 1985). The identifying relational processes in medical RAs were found mostly to be used to make definitions or descriptions, both of which are extremely important in medical discourse, for they provide the readers with the basic information or present an idea in an argument. For example:

(11) ||| Remifentanil is a unique mu opioid analgesic with an ultra-short duration of action due to its inactivation by non-specific esterases in plasma and tissues (Michelsen and Hug, 1996). ||| (J5-4)

(12) || ...the remaining compartments of the uterus showed a decrease that was not statistically significant. ||| (J3-2)

In Example 11, the Identifier "Remifentanil" was clearly defined as "a unique mu opioid analgesic with an ultra-short duration of action due to its inactivation by non-specific esterases in plasma and tissues". This definition supplies the readers with the basic information about the drug-Remifentanil. In Example 12, the Identifier "the remaining compartments of the uterus" was described as "a decrease that was not statistically significant", which presents some specific information of the uterus for the readers. In evidence, clauses of this 
kind will furnish the readers with some necessary information of the subject under discussion and give strong support for the argumentation to be made.

Relational processes hide human agency and downgrade actions into nominalizations (Halliday, 2000; Martinez, 2001) and are semantically impersonal, as they just show the relation between two concepts and do not involve agentive participants in their transitivity structure. The absence of agency makes the presented information more objective, impersonal and factual. In an English-medium medical RA, relational processes often serve as complements of the description of material processes and help produce more precise but less dull texts.

\subsubsection{Mental Processes}

For the purpose of achieving the objectivity of medical RAs, less personal involvement is one of the characteristics of medical RAs. Mental processes usually involve human beings' consciousness and thus are often viewed as somewhat subjective. Therefore, it is natural that mental processes are not very frequently used in medical RAs. However, proper use of mental processes with the Senser, such as "we" or the names of several researchers may provide space for medical writers to more effectively persuade the readers to accept their ideas. We found that in our corpus, 203 (49.6\%) of the 409 mental processes with the Senser used "we" or the names of several researchers as the Senser. For example:

(13) ||| We hypothesize $\|$ that through this mechanism, $E_{2}$ couples the daily neural signal to the surge-releasing mechanism, || and thereby prompts appropriately timed release of the preovulatory CnRH surge. ||| (J3-1)

In Example 13, the Senser "We", the participant endowed with consciousness, suggested the writers' hypothesis with a statement of their opinion "that through this mechanism, E2 couples the daily neural signal to the surge-releasing mechanism, and thereby prompts appropriately timed release of the preovulatory CnRH surge". Among other things, the application of the mental process with the Senser "we" or the names of several researchers may increase the sense of reliability of the RAs because more than one person, as indicated by the Senser, have endorsed the accuracy, quality and meaning of the results (Beaver, 2001; Thagard, 1997).

$\mathrm{Wu}$ (2004) further confirmed the persuasive function of mental processes in his study of English e-mails used for academic discussion (hereafter academic e-mails). Jiang reported that mental processes in academic e-mails reached a high percentage of over $40 \%$, which well conformed to the interactive and persuasive style of the discourse of academic e-mails. Though the findings of our study show that the percentage of mental processes used in English-medium medical RAs is significantly lower than that in academic e-mails, the relatively higher percentage of mental processes (12.97\%), ranking the third of the six process types in English-medium medical RAs, well exhibits medical RA writers' effort to persuade the readers to accept their ideas.

\subsubsection{Verbal Processes}

Verbal processes mainly dealing with "who says what to whom" are believed to have an undertone of subjectivity. The low occurrence frequency of verbal processes $(393,6.38 \%)$ in English-medium medical RAs, a kind of objectivity-focused academic writing, on the one hand provides evidence for this tendency but, on the other hand, shows that the function of verbal process is not totally overlooked by medical RA writers. Like that of mental processes, proper application of verbal processes also demonstrates the medical RA writers' effort to persuade the readers to accept their findings.

(14) $\| \mid$...both major secondary efficacy measures showed $\|$ that pactimibe treatment attenuated the regression of atherosclerosis observed in the usual-care group. $\| \mid(\mathrm{J} 1-1)$

In Example 14, the Sayer "both major secondary efficacy measures" is not a conscious participant but a kind of signal. The Verbiage "pactimibe treatment attenuated the regression of atherosclerosis observed in the usual-care group" presents the writer's findings and the application of a verb process fulfils the writers' intention of presenting the findings. In medical RAs, the Sayer of some verbal processes can also be authoritative researchers or institutes that own deep insight into the field or take lead in the discipline under discussion. The Sayer thus used will no doubt add the authority to the argumentation of the medical writer.

(15) ||| The largest U.S. study of first-trimester screening to date, involving 8514 pregnancies, reported a 79 percent detection rate at a 5 percent false positive rate. ||$(\mathrm{J} 1-2)$

In Example 15, the results of a largest-scale study were used by the writers to show readers the background information and lend support to their study. The Sayer, "The largest U.S. study of first-trimester screening to date, involving 8514 pregnancies", clearly indicates the authority of the study through the declaration of its being the largest scale study in the United States. The Verbiage "a 79 percent detection rate at a 5 percent false positive rate" directly presented by the Sayer apparently adds strength to the writers' argumentation. In her study of 
international political news, Yang (2004) also found that the use of verbal processes in speeches of government officials or their answers to journalists' questions was as high as $24 \%$, indicating that the use of verbal processes could reflect the authority of the news. By the same token, Sayers in medical RAs, such as reputable research institutes or prestigious experts, will also enhance the authority, reliability and persuasiveness of the medical RAs.

\subsubsection{Existential Processes}

A very low occurrence frequency of existential processes $(177,2.87 \%)$ was found in our corpus. Existential processes concern whether or not something exists or happens (Halliday, 2000). Since the purpose of the medical research is to a large extent to find the interrelationship between already existing entities in the actual world or to create or invent new entities for the benefit of human beings, it may be reasonable to find fewer existential processes but more relational and material processes in a medical RA. However, existential processes are often used when objectivity is emphasized (Jin, 1996). Like relational processes, existential processes can also hide human agency, and the appropriate application of existential processes may also help maintain the objectivity of the discourse.

(16) I|| There may even be an increased potential for interchromosomal interactions between enhancers and promoters. ||| (J4-3)

In Example 16, the existent, "an increased potential for interchromosomal interactions between enhancers and promoters", is presented as the only participant, which deliberately distances researchers from the discourse and focuses readers' attention on the hypothesis. In this way, the existential process adds force to the objectivity of the discourse.

\subsection{Transitivity Structure and Stylistic Features of Medical Ras}

RAs are the most important channel for presenting new knowledge in various fields (Hyland, 2000; Salager-Meyer, 2001; Swales, 2001) and their stylistic features are generally acknowledged as neutral, accurate, objective, argumentative and persuasive by many researchers (Hyland, 1998, 2000; Nwogu, 1997; Salager-Meyer, 1999, 2001; Swales, 2001, 2004). As an established genre and one of the most important channels for medical presentation and exchange of new findings in today's medical arena, the medical RA is no exception. Our findings suggest that some stylistic features of English-medium medical RAs, to a wide extent, are revealed by an analysis of the transitivity structure in medical RAs.

Our analysis of the application of the transitivity system embodied in the six process types in English-medium medical RAs reveals that the transitivity structure contributes to the realization of the stylistic features of being objective, argumentative, persuasive and informative in medical RAs. Generally speaking, the dominant use of the material process $(46.11 \%)$ objectively encodes how medical phenomena act or happen in the real world. The relational process $(31.62 \%)$ serves as the complements of the description of the material process and supplies the readers with the information needed to understand the text. Together, the percentages of the material process and the relational process account for more than $70 \%$ at both the article level and the section level, which just reflect the important features of objectivity and informativeness of a medical RA. The mental process $(13.00 \%)$ and the verbal process $(6.39 \%)$ are employed to fulfill particularly the argumentative and persuasive functions, while the low percentage of the existential process $(2.88 \%)$ indicates that for the purpose of the objectivity, the existential process is rarely used in English-medium medical RAs.

The different percentages of clusters of transitivity structure in different sections of an English-medium medical RA are associated with the respective central goals of the section and mirror in each section the degree of objectivity, argumentation, persuasion, informativeness and accuracy which characterize the section. In the Introduction section, a decision section about the amount and type of background knowledge, the winsomeness of the appeal to the readership, the directness of the approach (Swales, 2001) and an authoritative versus a sincerer stance (Arrington \& Rose, 1987), material, relational and mental processes are found to be most frequently used. The relatively high frequency of the verbal process in this section may contribute to the authority of the study. The transitivity structure in the Introduction section thus provides considerable and authoritative information about the question to be answered in a study, the significance of the question and a review of past research on the question being investigated. In the Method section, which was often dominated by "objects of research" (Martinez, 2003), the application of the material process, especially the agentless material process, well suits the style of the objective and detailed description of the research practices and methods employed in the study, including exactly how the research is carried out, how the subjects are selected and what statistical techniques are used to evaluate the significance of the findings. The low frequencies of the interpersonal processes (the mental process and the verbal process) in the Method section may reflect the 
medical writers' intention of avoiding subjective or personal evaluation, thus further enhancing the objectivity of this section. In the Results section, the place where new findings are highlighted, interpreted and commented upon by authors (Brett, 1994), medical RA writers tend to employ the relational process and the existential process to describe and analyze their findings, with the apparent intent to retreat from interpersonal intervention, thus emphasizing the objectivity and accuracy of the information presented in the section. In the Discussion section, medical RA writers assess and interpret the data obtained in relation to the problem presented, and attempt to persuade the readers of the relevance of the findings in relation to other findings, leading to the construction of knowledge (Hunston, 1994). The frequent use of the relational process in this section may allow the medical RA writers to withdraw to the background and evaluate the findings objectively, and the use of the mental process and the relational process in the section gives the writers the power to strengthen their argumentation and persuasion.

\section{Conclusion}

Our findings manifest that the transitivity system plays an important role in the realization of the stylistic features of the English-medium medical RA and that appropriate application of different process types in different sections in the English-medium medical RA may be related to the purposes and style requirements of each section. In line with the different styles as well as the goals of each section, medical writers employ different process types to objectively and accurately present detailed information, to argue for explanation and justification of their observations and to persuade the readers to accept the findings and interpretations of new claims. While the research on the genre structure of the English-medium medical RA gives medical RA writers a clear picture of "a distinctive category of discourse" (Swales, 2001, p. 33) in different sections in the medical RA, studies on the transitivity system of process types we hope will offer NNES medical writers some proper means to be employed in the realization of the discourse purposes of the genre structure in the medical RA.

The findings of our study have some pedagogical implications. NNES medical RA writers' better awareness of the transitivity system in English-medium medical RAs may help them more consciously and effectively use proper process types to unpack the information in the style required by the medical RA. The findings of our research can also be applied in English-medium medical RA writing courses for NNES medical RA writers. Proper application of the six process types from the perspective of the different style requirements of the Introduction, the Method, the Results and the Discussion sections in an English-medium medical RA may help NNES medical RA writers to produce stylistically appropriate medical RAs, and eventually lead to the ultimate goal of successful publication.

\section{Reference}

Aaronson, S. (1977). Style in scientific writing. Current Contents, 2, 6-15.

Adams-Smith, D. E. (1983). Style in medical journals. Br Med J (Clin Res Ed), 287(6399), 1122-1124. http://dx.doi.org/10.1136/bmj.287.6399.1122

Arrington, P., \& Rose, S. K. (1987). Prologues to what is possible: Introductions as metadiscourse. College Composition and Communication, 38(3), 306-318. http://dx.doi.org/10.2307/357750

Aston, G. (1997). Small and large corpora in language learning. In B. Lewandowska-Tomaszczyk, \& J. P. Melia (Eds.), Practical applications in language corpora (pp. 51-62). Lodz, Poland: Lodz University Press.

Babii, E., \& Ansary, H. (2005). On the effect of disciplinary variation on transitivity: The case of academic book reviews. Asian EFL Journal, 7(3), Article 10.

Bazerman, C. (1994). Constructing Experience. Carbondale: Southern Illinois University Press.

Beaver, D. D. (2001). Reflections on scientific collaboration (and its study): Past, present and future. Scientometrics, 52, 365-377. http://dx.doi.org/10.1023/A:1014254214337

Bonifacio, T. C. (2011). Using transitivity as a framework in a stylistic analysis of Virginia Woolf's Old Mrs. Grey. Asian EFL Journal, 54, 69-79.

Brett, P. (1994). A genre analysis of the results section of sociology articles. English for Specific Purposes, 13(1), 47-59. http://dx.doi.org/10.1016/0889-4906(94)90024-8

Crystal, D., \& Davy, D. (1969). Investigating English style. Bloomington: Indiana University Press.

Estevez, N., \& Pique, J. (1997). A process and product oriented approach to writing medical essays. In J. Pique, \& D. Viera (Eds.), Applied languages: Theory and practice in ESP (pp. 119-138). Valencia: Universitat de Valencia. 
Fowler, R. (1981). Literature as social discourse. London: Batsford.

Freeborn, D. (1996). Style: Text analysis and linguistic criticism. Houndmills Hampshire: Macmillan.

Gong, J., \& Fang, Y. (2005). An ideational functional analysis of argumentative discourse in English courts. Foreign Languages Research, 2005(3), 11-16.

Grant, J., \& Laird, A. (1997). Writing for medical journals. Current Obstetrics \& Gynaecology, 1997(7), 149-155. http://dx.doi.org/10.1016/S0957-5847(97)80077-7

Halliday, M. A. K. (1967). Notes on transitivity and theme in English, Part 1. Journal of Linguistics, 1967(3), 37-81. http://dx.doi.org/10.1017/S0022226700012949

Halliday, M. A. K. (1971). Linguistic function and literary style: An inquiry into the language of William Golding's The Inheritors. In S. Chatman (Ed.), Literary style: A symposium (pp. 45-47). New York: Oxford University Press.

Halliday, M. A. K. (1976). Types of process. In G. R. Kress (Ed.), Halliday: System and Function in Language (pp. 159-173). London: Oxford University Press.

Halliday, M. A. K. (1985). Ch.3 dimensions of discourse analysis: Grammar. In T. A. Van Dijk (Ed.), Handbook of Discourse Analysis: Vol. 2. Dimensions of discourse (pp. 29-56). London: Academic Press.

Halliday, M. A. K. (1988). On the language of Physical Science. In M. Ghadessy (Ed.), Register of Written English: Situational Factors and Linguistic Features (pp. 162-178). London: Pinter Publishers.

Halliday, M. A. K. (2000). An Introduction to Functional Grammar (2nd ed.). London: Edward Arnold/Beijing: Foreign Language Teaching and Research Press.

Halliday, M. A. K. (2001). Language as social semiotic: The social interpretation of language and meaning. Beijing: Foreign Language Teaching and Research Press.

Halliday, M. A. K. (2008). An introduction to functional grammar (3rd ed.). London: Edward Arnold/ Beijing: Foreign Language Teaching and Research Press.

Halliday, M. A. K., \& Martin, J. R. (1993). Writing science: Literacy and discursive power. London: The Palmer Press.

Halliday, M. A. K., \& Matthiessen, C. N. I. M. (2004). An introduction to functional grammar. London: Hodder Arnold.

Hemminki, E. (1982). Quality of clinical trials-A concern of three decades. Methods in Information in Medicine, 1982(21), 81-85.

Hopper, P. J., \& Thompson, S. A. (1980). Transitivity in grammar and discourse. Language, 56(2), 251-299. http://dx.doi.org/10.2307/413757

Hu, Z. L. (1994). Discourse cohesion and coherence. Shanghai: Shanghai Foreign Language Education Press.

Hunston, S. (1994). Evaluation and organisation in a sample of written academic discourse. In M. Coulthard (Ed.), Advances in written text analysis (pp. 191-218). London: Routledge.

Hyland, K. (1998). Hedging in Scientific Research Articles. Amsterdam: Benjamins. http://dx.doi.org/10.1075/pbns.54

Hyland, K. (2000). Disciplinary discourses: Social interactions in academic writing. Harlow: Pearson Education.

Jin, J. L. (1996). A contrastive study of English and Chinese existential sentences. Journal of Foreign Languages, 1996(6), 10-16.

Ju, Y. M. (2004). A quantitative study of the style of sports news in English newspapers. Foreign Languages Research, 2004(2), 23-27.

Knorr-Cetina, K. D. (1981). The manufacture of knowledge. Oxford: Pergamon.

Langacker, R. W. (1987). Foundations of cognitive grammar (Vol. 1). Stanford: Stanford University Press.

Li, M. X. (2006). Functional Grammar: A Course Book. Beijing: Foreign Languages Press.

Liu, S. S. (1998). Outlines of Western Stylistics. Jinan: Shandong Education Press.

Martinez, I. (2001). Impersonality in the research article as revealed by analysis of the transitivity structure. English for Specific Purposes, 20(3), 227-247. http://dx.doi.org/10.1016/S0889-4906(00)00013-2 
Martinez, I. (2003). Aspects of theme in the method and discussion sections of biology journal articles in English. Journal of English for Academic Purposes, 2003(2), 103-123. http://dx.doi.org/10.1016/S1475-1585(03)00003-1

Nash, W. (1990). Introduction: The stuff these people write. In W. Nash (Ed.), The writing scholar: Studies in academic discourse (pp. 8-30). Newbury Park, California: Sage Publications.

Nwogu, K. N. (1997). The medical research paper: Structure and functions. English for Specific Purposes, 16(2), 119-138. http://dx.doi.org/10.1016/S0889-4906(97)85388-4

O'Toole, M. (1988). Functions of Style. London: Pinter.

Okamura, A. (2006). Two types of strategies used by Japanese scientists, when writing research articles in English. System, 2006(34), 68-79. http://dx.doi.org/10.1016/j.system.2005.03.006

Paltridge, B. (1993). Writing up research: A systemic functional perspective. System, 1993(21), 175-192. http://dx.doi.org/10.1016/0346-251X(93)90040-N

Pang, J. X., \& Chen, M. Y. (2007). Transitivity in research articles and therealization of communicative aims: A genere analysis perspective. Journal of Foreign Languages, 2007(5), 16-22.

Roe, P. (2000). The ASTCOVEA German grammar in context project. In B. Dodd (Ed.), Working with German corpora (pp. 199-216). Birmingham, England: University of Birmingham Press.

Salager-Meyer, F. (1999). Referential behavior in scientific writing: A diachronic study (1810-1995). English for Specific Purposes, 8(3), 279-305. http://dx.doi.org/10.1016/S0889-4906(97)00042-2

Salager-Meyer, F. (2001). From self-highlightedness to self-effacement: A genre-based study of the socio-pragmatic function of criticism in medical discourse. LSP \& Professional Communication, 1(2), 63-85.

Shen, D. (1997). Some reflections on functional stylistics. Journal of Foreign Languages, 1997(5), 1-7.

Shen, D. (2002). Reconsideration on functional stylistics. Foreign Language Teaching and Research, 34(3), 188-193.

Short, M. H. (1976). Why we sympathize with Lennie. Mal Journal (New Series), 1976(1), 1-9.

Short, M. H. (1996). Exploring the language of poems, plays and prose. London: Longman

Swales, J. M. (2001). Genre Analysis: English in Academic and Research Settings. Cambridge: Cambridge University Press.

Swales, J. M. (2004). Research genres: Explorations and applications. Cambridge: Cambridge University Press. http://dx.doi.org/10.1017/CBO9781139524827

Thagard, P. (1997). Coherent and creative conceptual combinations. In T. B. Ward, S. M. Smith, \& J. Viad (Eds.), Creative thought: An investigation of conceptual structures and processes. Washington DC: American Psychological Association. http://dx.doi.org/10.1037/10227-006

Thompson, G. (2000). Introducing Functional Grammar. London: Arnold/Beijing: Foreign Language Teaching and Research Press.

Tribble, C. (1997). Improvising corpora for ELT: Quick and dirty ways of developing corpora for language teaching. In B. Lewandowska-Tomaszczyk, \& P. J. Melia (Eds.), Practical applications in language corpora (pp. 106-118). Lodz, Poland: Lodz University Press.

Wales, K. A. (1989). Dictionary of Stylistics. London: Longman.

$\mathrm{Wu}$, J. S. (2004). A multi-dimensional stylistic analysis of "academic E-mails". Foreign Language and Their Teaching, 2004(2), 53-57.

Yang, X. Y. (2001). A study of the style of editorial English. Foreign Language Teaching and Research, 33(5), 367-373.

Yang, X. Y. (2004). The stylistic characteristics of international politics news English. Foreign Languages Research, 2004(3), 31-37.

Zhang, D. L. (2005). Function and style of language. Beijing: Higher Education Press. 
Note

Note 1. By complete RAs, it is meant the body part of the text, i.e., the plain text only, without abstracts, figures/charts /tables, captions, footnotes, reference lists, and acknowledgements etc.

\section{Appendix A}

Halliday's (2008) criteria for distinguishing the process types

\begin{tabular}{|c|c|c|c|c|c|c|c|c|c|}
\hline & \multirow{2}{*}{\multicolumn{2}{|c|}{ Material }} & \multirow{2}{*}{ Behavioral } & \multirow{2}{*}{\multicolumn{2}{|c|}{ Mental }} & \multirow{2}{*}{ Verbal } & \multicolumn{2}{|c|}{ Relational } & \multirow{2}{*}{ Existential } \\
\hline & & & & & & & Attributive & Identifying & \\
\hline $\begin{array}{l}\text { Category } \\
\text { meaning: }\end{array}$ & $\begin{array}{l}\text { doing (do } \\
\text { happenin } \\
\text { to/with) }\end{array}$ & doing & behaving & sensing & & saying & $\begin{array}{l}\text { being } \\
\text { (attribute) }\end{array}$ & $\begin{array}{l}\text { being } \\
\text { (identity) }\end{array}$ & $\begin{array}{l}\text { being } \\
\text { (existence) }\end{array}$ \\
\hline $\begin{array}{l}\text { Number of } \\
\text { inherent } \\
\text { participants: }\end{array}$ & \multicolumn{2}{|l|}{1 or 2} & 1 & \multicolumn{2}{|l|}{2} & 1 & 1 & 2 & 1 or 0 \\
\hline $\begin{array}{l}\text { Nature of first } \\
\text { participant: }\end{array}$ & \multicolumn{2}{|l|}{ thing } & $\begin{array}{l}\text { conscious } \\
\text { thing }\end{array}$ & \multicolumn{2}{|c|}{ conscious thing } & $\begin{array}{l}\text { symbol } \\
\text { source }\end{array}$ & thing or fact & $\begin{array}{l}\text { thing } o r \\
\text { fact }\end{array}$ & $\begin{array}{l}\text { thing } o r \\
\text { fact }\end{array}$ \\
\hline $\begin{array}{l}\text { Nature of } \\
\text { second } \\
\text { participant: }\end{array}$ & \multicolumn{2}{|l|}{ thing } & & \multicolumn{2}{|c|}{ thing or fact } & & & $\begin{array}{l}\text { [same as } \\
1 \mathrm{st}]\end{array}$ & \\
\hline $\begin{array}{l}\text { Ability to } \\
\text { project }\end{array}$ & \multicolumn{2}{|l|}{-} & - & \multicolumn{2}{|c|}{ projection of ideas } & $\begin{array}{l}\text { projection } \\
\text { of } \\
\text { locutions }\end{array}$ & - & - & - \\
\hline Directionality: & \multicolumn{2}{|l|}{ one way } & one way & $\begin{array}{l}\text { two way: } \\
\text { please } \\
\text { type }\end{array}$ & like type & one way & one way & one way & one way \\
\hline Voice: & $\begin{array}{l}\text { middle } \\
\text { or } \\
\text { effective }\end{array}$ & & middle & effective & middle & $\begin{array}{l}\text { middle } \text { or } \\
\text { effective } \\
\text { [target } \\
\text { type] }\end{array}$ & $\begin{array}{l}\text { middle } o r \\
\text { effective }\end{array}$ & $\begin{array}{l}\text { middle } o r \\
\text { effective }\end{array}$ & middle \\
\hline $\begin{array}{l}\text { Type of } \\
\text { receptive: }\end{array}$ & & receptive & & receptive & $\begin{array}{l}\text { medio- } \\
\text { receptive }\end{array}$ & & & receptive & \\
\hline Pro-verb: & do & $\begin{array}{l}\text { do to/ } \\
\text { with }\end{array}$ & do & (do to) & & & & & \\
\hline $\begin{array}{l}\text { Unmarked } \\
\text { present tense: }\end{array}$ & \multicolumn{2}{|c|}{ present in present } & $\begin{array}{l}\text { present in } \\
\text { present }\end{array}$ & \multicolumn{2}{|c|}{ simple present } & $\begin{array}{l}\text { simple } \\
\text { present }\end{array}$ & $\begin{array}{l}\text { simple } \\
\text { present }\end{array}$ & $\begin{array}{l}\text { simple } \\
\text { present }\end{array}$ & $\begin{array}{l}\text { simple } \\
\text { present }\end{array}$ \\
\hline $\begin{array}{l}\text { Accentuation } \\
\text { of verb: }\end{array}$ & \multicolumn{2}{|l|}{ accented } & accented & accented & (either) & (either) & unaccented & unaccented & unaccented \\
\hline
\end{tabular}




\section{Appendix B}

\section{Verbs proposed by Halliday (2008) and Thompson (2000) in realizing the five processes}

\begin{tabular}{|l|l|}
\hline Material & $\begin{array}{l}\text { do, spring, catch, resign, dissolve, combine, play, go, fetch, fall, } \\
\text { break, mend, etc. }\end{array}$ \\
\hline Mental & $\begin{array}{l}\text { sense, like, please, feel, think, perceive, long for, know, see, believe, } \\
\text { hear, fear, understand, etc. }\end{array}$ \\
\hline Relational & $\begin{array}{l}\text { be, play, act as, serve as, mean, indicate, suggest, imply, show, } \\
\text { betoken, mark, reflect, equal, make, comprise, include, represent, } \\
\text { constitute, form, exemplify, illustrate, express, signify, realize, spell, } \\
\text { stand for, become, remain, etc. }\end{array}$ \\
\hline Verbal & $\begin{array}{l}\text { look, watch, stare, listen, think, worry, dream, chatter, grumble, talk, } \\
\text { cry, laugh, smile, frown, sigh, snarl, whine, breathe, cough, faint, shit, } \\
\text { yawn, sleep, sing, dance, lie, sit, etc. }\end{array}$ \\
\hline Existential & $\begin{array}{l}\text { say, tell, ask, describe, repeat, outline, explain, order, promise, speak, } \\
\text { imply, indicate, show, demonstrate, signify, suggest, etc. }\end{array}$ \\
\hline $\begin{array}{l}\text { be, exist, remain, arise, occur, come about, happen, take place, } \\
\text { follow, ensue, sit, stand, lie, hang, rise, stretch, emerge, grow, erupt, } \\
\text { flourish, prevail, etc. }\end{array}$ \\
\hline
\end{tabular}

\section{Copyrights}

Copyright for this article is retained by the author(s), with first publication rights granted to the journal.

This is an open-access article distributed under the terms and conditions of the Creative Commons Attribution license (http://creativecommons.org/licenses/by/3.0/). 